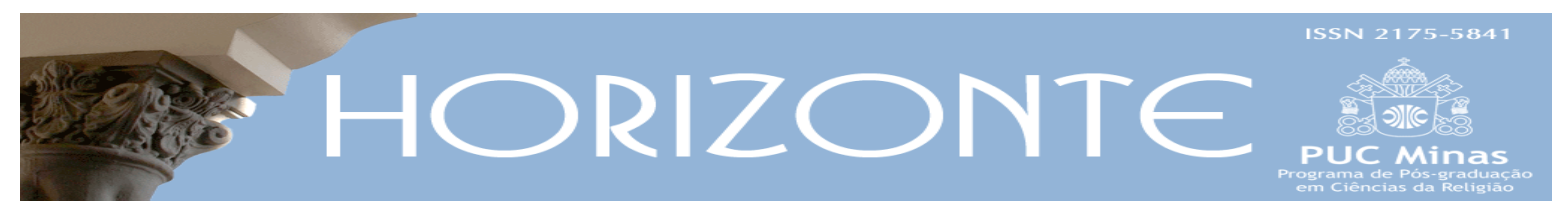

Dossiê: Teorias de linguagem e Estudos de Religião - Artigo Original ๑을

\title{
Linguagem, memória e religião no pensamento de Maurice Halbwachs
}

\author{
Language, memory and religion in Maurice Halbwachs Thought
}

\author{
Dario Paulo Barrera Rivera*
}

\begin{abstract}
Resumo
Na obra de Maurice Halbwachs, pensador das primeiras décadas do século XX, se encontra uma reflexão sobre a relação entre linguagem e memória. Trata-se de uma reflexão precoce, pois acontece numa época bem anterior ao desenvolvimento da filosofia da linguagem e à "virada linguística". Esse artigo apresenta a forma como Halbwachs entendia a relação entre linguagem e memória. O pensamento de Maurice Halbwachs é ainda pouco conhecido no campo dos estudos de religião na América Latina. Seus estudos pioneiros sobre a memória social e a memória religiosa foram retomados na França só no final do século XX. Os estudiosos do pensamento de Halbwachs e os estudiosos da religião tem prestado pouca atenção à forma como ele entendia a relação entre linguagem, memória e religião. A linguagem, o tempo e o espaço, são revisados neste texto como quadros sociais que dão suporte à memória coletiva. Destacamos na análise do tema proposto as caraterísticas da memória coletiva religiosa.
\end{abstract}

Palavras-chaves: memória; linguagem; religião; Maurice Halbwachs.

\begin{abstract}
Maurice Halbwachs was a thinker of the first decades of the twentieth century. He has a reflection on the relation between language and memory. This is an early reflection, because it happens at a time well before the development of the Philosophy of Language and too before the "linguistic turn." This article presents how Halbwachs understood the relation between language and memory. The Maurice Halbwachs thought is still little known in the field of Religion Studies in Latin America. His pioneering studies on social memory and religious memory were resumed in France only at the end of the twentieth century. Halbwachs' thinking scholars and scholars of religion have paid little attention to how he understood the relationship between language, memory, and religion. Language, time, and space are reviewed as social frameworks that support collective memory. We emphasize in the analysis of the proposed theme the characteristics of the religious collective memory.
\end{abstract}

Keywords: memory; language; religion; Maurice Halbwachs.

Artigo submetido em 19 de setembro de 2018 e aprovado em 20 de novembro de 2018.

* Doutor em Ciências da Religião pela Universidade Metodista de São Paulo. Professor titular da Universidade Metodista de São Paulo no Programa de Pós-graduação em Ciências da Religião. País de origem: Brasil. E-mail: dariopbr@terra.com.br 


\section{Introdução}

$\mathrm{Na}$ sociedade moderna caracterizada pela mudança acelerada, pela comunicação imediata, pela circulação generalizada de bens, capitais, pessoas, saberes, símbolos, imagens, etc., colocam-se as questões da memória e do esquecimento. Em que situação ficariam os "quadros sociais da memória" que no pensamento de Halbwachs são fundamentais para a permanência das instituições sociais. Junto ao tempo e o espaço, a linguagem é um dos quadros sociais da memória coletiva. Maurice Halbwachs foi um pensador da primeira metade do século XX. Passou da filosofia bergsoniana para a sociologia durkheimiana tornando-se um inovador desta última. Foi o primeiro a propor uma compreensão social da memória. Em seus escritos, ensaia uma explicação entre memória e linguagem.

Encontramos em Halbwachs algumas hipóteses sobre a relação entre linguagem e memória que se orientam, precocemente, em direção oposta às hipóteses de Henri Bergson. Muito antes da "virada linguística" da segunda metade do século XX, tanto Bergson quanto Halbwachs ensaiaram explicações sobre como linguagem e pensamento se relacionavam. $O$ primeiro, em perspectiva fenomenológica e psicológica, discorre, por exemplo, sobre o papel da "intuição" no processo do conhecimento (1930). Nessa perspectiva, o conhecimento não passaria necessariamente pela linguagem, como afirmado pela linguística mais recente (SAMPAIO, 2017). Por sua parte, Halbwachs, em perspectiva mais sociológica, não se interessa pela linguagem em si mesma e sim pela relação com o pensamento social e com a memória coletiva. Halbwachs preocupa-se menos pelo conteúdo da memória religiosa e muito com a forma como ela se processa. Nesse sentido, sua análise inclui postulados que só décadas depois seriam desenvolvidos pela filosofia da linguagem, mais preocupada na forma que encobre o que se diz do que propriamente naquilo que é dito. ${ }^{1}$ Halbwachs se interessa por explicar como

\footnotetext{
${ }^{1}$ Sampaio (2017, p. 47) destaca que "já há duas ou três gerações, aquilo que é dito interessa um pouco menos do que está encoberto na maneira ou na forma pela qual se pôde dizê-lo, e agora se compartilha a convicção de que nenhuma reflexão rigorosa deve prescindir de um exame sobre o que dá significado e quem sabe até constitui ao que é refletido".
} 
acontece o processo de memória, e não propriamente pelo conteúdo das lembranças.

Henri Bergson, mestre de Halbwachs, pensava que o pensamento e a memória eram fenômenos absolutamente individuais. Essa hipótese é central na sua obra Matéria e memória (1990). Halbwachs toma distância dele e critica a noção bergsoniana de "tempo universal". Percebe-se esse distanciamento na utilização do conceito de "corrente social”, utilizado por ele em Les Cadres sociaux de la mémoire (1925) e em La morfologie social (1970). Nas suas pesquisas sobre diversos outros temas, Halbwachs, se valeu de dados estatísticos e de pesquisa de campo. Por exemplo na sua tese de doutorado La classe ouvrière et les niveaux de vie. Recherches sur la hiérarchie des besoins dans les sociétés industrielles contemporaines (1913) pesquisando os orçamentos dos operários o autor mostra como os operários ficam isolados da matéria e desintegrados da sociedade. Mas, o tema da memória não podia ser estudado a partir de dados quantitativos. Diferente e contrário a Bergson (1990) que considerava a memória uma intuição individual de um passado limitado à consciência, Halbwachs, negando a homogeneidade do tempo e do espaço, afirma o caráter social do primeiro e a particularidade de cada espaço social.

Em La Topographie légendaire des évangiles en Terre sainte. Étude de mémoire collective (1971), o autor analisa os relatos mais antigos de peregrinos sobre a geografia do tempo de Jesus Cristo. Esse estudo o leva à conclusão de que a memória coletiva é versátil e a memória religiosa não está livre dessa questão. Tal versatilidade obedece às necessidades particulares dos grupos sociais, grupos de memória, em diferentes épocas e circunstâncias. Foi o que aconteceu com a memória coletiva cristã que adaptou as lembranças da vida de Jesus Cristo e dos lugares onde teriam acontecido às exigências e aspirações do cristianismo em diversas épocas. Vejamos, então, como Halbwachs entende os "quadros sociais" que dão suporte à memória coletiva e, na sequência, como aparece no seu pensamento a relação entre memória e linguagem. As implicações na memória 
religiosa que resultam da forma como nosso autor entende essa relação, serão expostas ao longo do texto.

\section{A memória coletiva se apoia em quadros sociais}

A contribuição mais importante de Halbwachs é, sem dúvida, que a memória é um processo sempre coletivo. ${ }^{2}$ Os quadros de referência da memória são sempre coletivos. Sem o auxílio de grupos sociais de pertença ou de processos culturais um indivíduo vê sua memória fragilizada. ${ }^{3} \mathrm{O}$ isolamento social interfere no processo de memória e, em consequência, na elaboração de uma identidade. Um elemento mínimo da identidade é a pertença a grupos sociais. Um indivíduo isolado é incapaz de lembrar porque lhe faltam os "quadros sociais" que lhe dão suporte. Também não tem condições de produzir uma pertença mínima que alimente uma identidade.

Entre a memória individual e a memória coletiva não há apenas uma diferença de grau. A memória coletiva não é uma superação dos limites da memória individual. A memória é sempre coletiva e resulta da trama entre as identidades individual e coletiva. Halbwachs defende essa hipótese apoiando-se em uma "parábola" registrada no "avant-propos" de Les Cadres sociaux de la mémoire (1925). A narrativa trata de uma jovem escrava encontrada num bosque (em 1731) que em decorrência de seu isolamento social e físico não é capaz de dizer quem é nem de onde vem. Também não guarda lembrança alguma de sua infância. Reunindo detalhes sobre diversos momentos de sua vida, supõe-se que a escrava nasceu no norte da Europa, provavelmente entre os esquimós. Que teria sido levada às Antilhas e depois à França. Ela ficava muito comovida quando lhe eram mostradas imagens e produtos da região esquimó. São essas imagens que lhe

\footnotetext{
2 Discutimos as implicações dessa característica da memória nos processos de transmissão da memória religiosa em nosso livro Tradição, transmissão e emoção religiosa (BARRERA, 2001). Retomamos, neste artigo, algumas ideias discutidas no capítulo I dessa obra.

${ }^{3}$ Percebe-se, na importância outorgada por Halbwachs aos processos coletivos, a influência do pensamento durkheimiano. Halbwachs foi parte da equipe de pesquisadores em torno de Durkheim, mas importa destacar que Halbwachs foi um inovador do próprio pensamento durkheimiano e foi além dos limites dessa escola. Interessou-se, por exemplo, pela questão das classes sociais e pelos processos da memória.
} 
ajudam a lembrar que era escrava de uma senhora que gostava muito dela; e que o patrão, que não a suportava, obrigou-a a embarcar.

A memória, assim, depende de suportes coletivos, de marcos sociais. Uma pessoa tirada bruscamente de seu meio social e transportada para uma outra sociedade na qual a língua, as pessoas, os lugares e os costumes são muito diferentes parece perder a faculdade de se lembrar do que fizera e daquilo que vivera. Para recuperar as lembranças foi necessário mostrar-lhe pelo menos algumas imagens do grupo e dos lugares de sua sociedade de origem. A jovem recupera uma identidade mínima no momento em que sua memória é ativada, mas essa não se ativa isoladamente, sem apoiar-se no grupo social implicado nas experiências lembradas. Nessa perspectiva pode se afirmar, com Halbwachs, que a memória é uma condição da identidade dos grupos e das pessoas. Ao mesmo tempo, a memória de um indivíduo isolado mostra-se incapaz de gerar uma identidade. Memória coletiva e identidade têm em comum o fato de ser resultado de processos coletivos.

No primeiro capítulo de Les Cadres sociaux de la mémoire (1925), titulado "Le rêve e les imagens-souvenirs", Halbwachs compara a memória ao sonho e mostra que o ato de lembrar implica um processo de decomposição e recomposição inserido numa atividade racional muito intensa. É do grupo que recebemos a confirmação de nossas lembranças. São as referências comuns ao grupo os guias que ativam nossa atividade memorial. Bergson também comparou o sonho à memória, mas numa perspectiva individual, afirmando que nos sonhos a totalidade de nosso passado se reproduz (1949). Diferente dessa ideia, Halbwachs (1994, p. 36) afirma a impossibilidade de reviver o passado no sonho, pois neste estado somos incapazes de realizar uma verdadeira atividade de memória.

Os quadros sociais da memória são grupos reais onde indivíduos partilham a vida. E a memória coletiva é realmente a memória do grupo: religioso, da classe social, da família, etc. Cada grupo tem caraterísticas próprias, mas, sempre será grupo de suporte indispensável para a memória. A memória familiar tem retratada 
sua densidade afetiva, sua irreversibilidade e sua forte continuidade. A memória religiosa é entremeada com conflitos, pois, diferentes das outras, tende a ser exclusiva. Na memória da classe social Halbwachs encontra a complexa relação entre história e memória. Todas essas memórias constituem uma força simbólica que fornece, aos membros desses grupos específicos, a possibilidade de construção de uma totalidade de sentido.

No capítulo La mémoire collective chez les musiciens, primeiro capítulo da obra La mémoire collective (1997), encontramos uma interessante reflexão sobre a relação entre memória e linguagem. A linguagem é para a memória como uma partitura para o músico que toca numa orquestra. A partitura, como a linguagem, só é eficaz porque se apoia em certo consenso sobre o sentido dos símbolos musicais. Para poder participar de uma orquestra é necessário saber ler a partitura. Para ser admitido num grupo de compositores, músicos ou apreciadores de obras musicais é preciso ter capacidade e sensibilidade para entender as múltiplas combinações de sons: tom, timbre, intensidade, velocidade, sequência, duração, entre outros. É preciso partilhar da mesma linguagem. Numa apresentação de orquestra, as pessoas podem conhecer a melodia, reconhecê-la se já a conheciam, reproduzi-la, reconstruí-la segundo seu gosto, etc. Seria impossível unificar a melodia sem um grupo de músicos conduzindo-a segundo uma formulação codificada da linguagem musical. Há um acordo prévio sobre o significado dos signos musicais. Esses últimos não têm sentido para quem tem nas mãos uma partitura mas ignora a existência da orquestra: seu sentido se revela no conjunto do qual fazem parte no momento da interpretação. A orquestra é uma metáfora da sociedade. Uma sociedade mantém um conjunto quando cada pessoa que toca um elemento da partitura reconhece, através dessa linguagem musical comum, o meio de unificação da melodia. A partitura é a linguagem comum indispensável para que a orquestra interprete uma música4. Temos aqui uma excelente comparação com a linguagem como suporte da memória. Como veremos na terceira parte deste artigo a linguagem, como a partitura, é também uma convenção social.

\footnotetext{
${ }^{4}$ Veja uma análise da metáfora utilizada por Halbwachs, comparada com a linguagem, em Gerard Namer (1987).
} 
Que a memória aconteça dentro de quadros sociais não significa que seja homogênea. É possível que cada indivíduo faça diferentes interpretações da melodia segundo sua sensibilidade. Mas, é preciso seguir a mesma linguagem, para poder tocar na orquestra e dar um valor à música. Halbwachs coloca a linguagem como quadro social da memória e questiona o isolamento de cada um dos quadros (linguagem, tempo e espaço). A linguagem deve ser considerada parte do quadro social de cada grupo particular, de forma semelhante ao tempo e ao espaço. Os músicos têm suas lembranças de notas, signos, regras, lugares e pessoas com as quais escutou ou interpretou pela primeira vez certa melodia. Essas recordações permanecem nele, pois fazem parte do grupo no qual ele as adquiriu; elas conservam-se numa memória coletiva que se estende (no espaço e no tempo) tanto quanto a sociedade ou o grupo ao qual pertencem. Halbwachs (1997, p. 34) propõe a seguinte questão: se na interpretação musical o ritmo é fundamental, um homem totalmente isolado pode descobrir as divisões rítmicas no espaço sonoro? Se algum fenômeno natural lhe sugerisse o ritmo, ele não precisaria recebê-lo de outras pessoas; mas os sons da natureza não seguem qualquer medida ou cadência. $\mathrm{O}$ ritmo é um produto da vida em sociedade: um indivíduo absolutamente só não saberia inventá-lo.

Um vínculo estreito entre linguagem e memória aparece de maneira nítida na metáfora do "solitário de Londres", utilizada por Halbwachs (1997, p. 52) para explicar o conceito de "correntes de memória”. Em síntese a metáfora utilizada é a seguinte: chego pela primeira vez a Londres e caminho pelos mesmos lugares várias vezes, acompanhado por pessoas diferentes. Um arquiteto chama minha atenção para os edifícios, para suas proporções e disposição. Com um historiador, aprendo que uma tal rua foi traçada numa determinada época, que em tal casa nasceu um homem muito conhecido e que aconteceram aqui ou acolá incidentes notáveis. Acompanhado por um pintor eu sou sensibilizado pela tonalidade dos parques, pela aparência dos palácios e igrejas, pelos jogos de luz e sombra nos muros e fachadas de Westminster, do Templo sobre o Tâmisa. Com um comerciante vou às ruas populares da cidade, vejo lojas e livrarias. Mesmo que eu não tenha caminhado ao lado de nenhum desses homens, será suficiente ter lido 
descrições da cidade - feitas a partir desses diversos pontos de vista - ter seguido as recomendações de alguém ou ter revisado a planta da cidade. Suponha-se que eu caminho totalmente só. É possível dizer que dessa caminhada eu só guardarei lembranças individuais relacionadas a mim? A solidão é apenas aparente: ao passar por Westminster eu pensei naquilo que o meu amigo historiador dissera ou em algo que eu lera. Atravessando uma ponte eu observei o efeito de perspectiva sobre o qual meu amigo pintor falara ou desenhara. Através do pensamento eu me recoloco nos diferentes grupos de que fiz parte. Outras pessoas compartilharam lembranças comigo e me ajudam a recordar; é por meio das lembranças que eu me remeto aos meus interlocutores e adoto provisoriamente o seu ponto de vista. As lembranças dos interlocutores com os quais o "solitário de Londres" partilhou sua intenção de visitar essa cidade reaparecem durante o passeio pela cidade. Sem a linguagem comum a eles essas lembranças não seriam possíveis. A linguagem, assim, é um quadro social que dá suporte à memória coletiva.

\section{Lugar e memória religiosa}

Em razão de sua materialidade o espaço é, para nosso autor, um importante quadro social da memória. Para Halbwachs, a memória religiosa depende de três elementos: lugares, pessoas e acontecimentos. Dentre essas três formas de fixação da verdade, o lugar tem maior possibilidade de se apresentar de maneira concreta. As pessoas e os acontecimentos são passageiros e podem ser imitados, mas não se repetem jamais. As pessoas não são instantâneas como os acontecimentos; durante o tempo de vida, elas podem contribuir com seus testemunhos para a fixação de uma lembrança. Os lugares, diferente das pessoas e acontecimentos, permanecem, oferecendo à memória certa estabilidade. É possível voltar ao lugar dos acontecimentos ou ao lugar onde as pessoas estiveram e encontrar o mesmo quadro espacial. É claro que ele já não será o mesmo depois dos acontecimentos e na ausência das pessoas, mas continuará oferecendo uma materialidade não encontrada nos outros elementos. Essa vantagem deve-se ao fato de que os lugares mudam em ritmo muito lento se comparado à fugacidade dos acontecimentos e à pequena duração das pessoas. 
No capítulo La mémoire collective et l'espace, Halbwachs apoia-se na estabilidade dos lugares para destacar sua importância na memória religiosa (1997, p. 193). Todo grupo com interesses permanentes articula-se em espaços comuns. $O$ território é indispensável para garantir a estabilidade de qualquer grupo, mas é também necessário que esse espaço partilhado seja estável no tempo. A transformação repentina do lugar comum implica novos desafios para a memória do grupo. Halbwachs utiliza o conceito de espaço social que só existe no tempo, na durabilidade e na permanência. No caso do grupo religioso, quando o lugar de memória comum é alterado, surge a necessidade de reconstruir (mesmo que de maneira artificial ou fictícia) o lugar original.

O grupo religioso, mais que outros grupos, precisa se apoiar sobre um objeto, sobre qualquer parte da realidade que dure, porque ele mesmo pretende não mudar, enquanto que em torno dele todas as instituições e costumes se transformam e as ideias e experiências se renovam. Enquanto que os outros grupos se preocupam em persuadir seus membros de que as suas regras e ordenanças permanecem iguais por determinado período, sempre limitado, a sociedade religiosa não pode admitir que ela não seja hoje tal como foi na sua origem, nem que ela tenha que mudar no futuro. Mas como no mundo dos pensamentos e dos sentimentos todo elemento de estabilidade foi defeituoso, então é na matéria, e sobre uma ou várias partes do espaço que ela deve garantir seu equilibro. (HALBWACHS, 1997, p. 228).

Diferente de outros grupos, como o grupo familiar ou o grupo de classe social, o grupo religioso precisa acreditar em sua estabilidade e permanecer fiel às suas origens e tradições. Qualquer mudança (sinônimo de instabilidade) é mal recebida porque o grupo religioso é naturalmente tradicional. Ele deve preservar a ilusão de não mudança enquanto tudo muda em torno dele. Essa é evidentemente uma ilusão, mas, ilusão necessária5. A materialidade dos lugares sagrados é ilusória pois a grande maioria dos fiéis não pode nem precisa visitá-los para certificar-se de sua existência. É suficiente imaginá-los, vê-los representados nos locais de culto e

\footnotetext{
${ }^{5}$ Retomando questões desenvolvidas em La topographie legendaire des Evangiles en Terre sainte, Halbwachs (1997, p. 230) diz em La mémoire collective: "Quando os cruzados chegaram a Jerusalém e tomaram posse dos lugares santos, não se contentaram em localizar os lugares onde a tradição colocava os principais acontecimentos narrados nos Evangelhos. Logo localizaram, mais ou menos arbitrariamente, alguns detalhes da vida de Cristo ou da Igreja primitiva cristã, guiando-se por vestígios incertos e mesmo na ausência de todo vestígio, obedecendo à inspiração do momento. Depois, com a vinda de peregrinos para orar nesses lugares, novas tradições se formaram, a tal ponto que hoje é muito difícil distinguir as lembranças dos lugares que remontam aos primeiros séculos da era cristã de tudo aquilo que a imaginação religiosa adicionou".
} 
saber da sua permanência. A materialidade dos lugares é virtual mas deve passar a ideia de estabilidade, a ilusão de não mudança.

Em Les Cadres sociaux de la mémoire, Halbwachs diz que o grupo religioso caracteriza-se por uma memória conflituosa, de combate: "A memória do grupo religioso, para se constituir, tem que impedir que outras memórias se formem ou se desenvolvam em torno dela" (HALBWACHS, 1994, p. 193). Ela é também uma memória composta, constituída por elementos provenientes de fontes distintas. Ao estudar a constituição de uma tradição religiosa, Halbwachs enfatiza o trabalho de unificação que as religiões empreendem a partir das contribuições recebidas de diferentes componentes da sociedade.

Pode-se dizer de toda religião que, sob formas mais ou menos simbólicas, ela reproduz a história das migrações e das fusões de raças e de povos, dos grandes eventos, guerras, estabelecimentos, invenções e reformas que se encontrariam na origem das sociedades que as praticam. (HALBWACHS, 1994, p. 178).

A religião tem uma grande capacidade de apropriar-se dessas contribuições e recolocá-las em novos dispositivos de sistematização. Halbwachs dá muitos exemplos de religiões antigas que se alimentaram de outras crenças. Sua análise parte do princípio de que todo pensamento coletivo sistematiza (a partir dos conceitos atuais) os ritos e crenças passadas que não desapareceram. A religião faz uma síntese constantemente reelaborada. Essa interpretação altera o sentido e a forma das antigas instituições (HALBWACHS, 1994, p. 182), mas, passa como se nada tivesse sido alterado.

Se a religião é uma espécie de adaptação, todo tipo de reativação é possível, pois novas circunstâncias ou novas contingências podem ser colocadas para o grupo religioso. As religiões que pretendem sempre permanecer ao longo do tempo estarão na necessidade de encarar as mudanças sociais, inevitáveis e autónomas à própria religião. O enfraquecimento das crenças antigas corresponde aos interesses de grupos em determinado estado de desenvolvimento; elas podem ser reativadas em novas circunstâncias sociais. Para Halbwachs, não há retorno de religião nem ressurreição do passado: as novas aspirações sociais recorrem às crenças antigas, 
marginalizadas pela religião oficial, na tentativa de impor um novo modelo religioso. A recriação das crenças se faz a partir de dados sociais e culturais novos, mesmo quando essas invocam uma tradição imemorial. Para o autor, há uma estreita relação entre sobrevivência e recriação no cenário religioso. A primeira corresponde à presença de grupos retardatários na sociedade; para eles, as crenças marginalizadas têm uma pertinência ativa ou pelo menos semiativa. Isso é discutível para a sociedade contemporânea, na qual há camadas plenamente integradas - e, portanto, não retardatárias - que reativam antigas crenças. Essa reativação ocorre por meio de formas mais sutis de reapropriação simbólica e cultural.

Halbwachs considera o cristianismo um excelente exemplo de reativação seletiva da memória. O cristianismo constitui-se como religião sublinhando sua descontinuidade em relação ao judaísmo tradicional; ao mesmo tempo, a religião cristã não se compreende sem referência à tradição judaica. A inovação religiosa nunca é absoluta e está subordinada à necessidade de continuidade tradicional, suporte da sua legitimidade; isso é próprio de todo pensamento religioso. A religião cumpre a função social de integrar o passado ao presente porque ela só se renova remetendo-se (mesmo que de forma ilusória) às suas origens: "Se a sociedade conserva, na sua organização religiosa, elementos de ritos ou de crenças antigas, é não só para dar satisfação às exigências dos grupos mais retardatários, mas, para sentir exatamente uma continuidade ou um progresso religioso que os homens devem se lembrar, ao menos grosso modo, de onde eles partiram" (HALBWACHS, 1994, p. 184). A memória religiosa que se apoia nos lugares de origem, regra geral passa por essas contingencias resultantes de mudanças nos lugares sagrados de origem acontecidas ao longo do tempo.

\section{Tempo social e memória religiosa}

O caráter religioso de uma crença reside num tipo particular de mobilização da memória que faz da lembrança, indefinida no tempo e no espaço, o momento fundador de uma verdade considerada atemporal. Em La mémoire collective 
(1997), especialmente no capítulo La mémoire collective et le temps, Halbwachs distingue uma natureza temporal dupla: o tempo como eterno presente dos fatos vividos e como fenômeno social; essa última natureza é múltipla e corresponde a cada esforço de memória, pois toda memória se apoia num tempo social.

O autor parte da premissa de que a existência de uma representação temporal coletiva é indispensável. A divisão social do tempo é resultado de convenções que expressam uma ordem de sucessão das diferentes fases da vida coletiva. A uma organização natural do tempo (dia e noite, estações do ano) se superpõe outra organização baseada nas condições e hábitos dos grupos humanos concretos. Aos poucos, a natureza delega aos homens a responsabilidade de organizar a divisão e a duração do tempo, sem que a sociedade consiga escapar da repetição. Esta é menos incômoda do que a uniformidade do tempo; a padronização temporal incide sobre todos os membros de uma sociedade e impõe uma disciplina: todos somos obrigados a medir o tempo e a respeitar suas divisões. Mas a duração temporal não tem o mesmo sentido para todas as pessoas, especialmente quando se trata das lembranças. O tempo transcorrido entre dois acontecimentos parece vazio e sem medi-lo seria impossível contar com pontos de referência úteis para todas as consciências. Cada pessoa terá uma consciência da duração, pois o tempo transcorrido teve conteúdos diferentes para cada indivíduo: horas ou dias vazios, fatos precipitados, percepção acelerada de certos acontecimentos devido à exaltação, à efervescência afetiva. A simultaneidade não garante a uniformidade da consciência temporal.

Halbwachs critica a noção bergsoniana de tempo universal - que envolve todas as existências e todos os fenômenos sucessivos - entendendo-o como sequência descontínua de momentos. O tempo social é bem mais complexo: é uma criação artificial que deriva não só da adição de momentos como também da combinação e da multiplicação de dados emprestados das durações individuais. A simultaneidade torna-se um quadro social da memória porque cada indivíduo supõe que a sua percepção do mundo exterior é total. Essa análise suscita o sério 
problema de como fazer sociologia a partir de um conjunto de pensamentos individuais.

A proposta de uma dupla natureza do tempo é uma resposta de Halbwachs a Bergson. Para aquele, a resposta imediata da consciência é a "memória coletiva” e não o que Bergson chama de "consciência individual", apoiando-se na simultaneidade para demonstrar a independência das consciências individuais. Halbwachs indica que a independência só acontece no interior de uma experiência coletiva das consciências. Ele supera o cerco da multiplicidade de consciências individuais recorrendo ao conceito de "correntes de pensamento", conceito que constitui uma contribuição original de Halbwachs à sociologia da memória:

Em nosso pensamento, na realidade, cruzam-se a cada momento ou a cada período de seu desenvolvimento muitas correntes que vão de uma consciência a outra, e das quais nossa consciência é o lugar de encontro. Sem dúvida que, a aparente continuidade disso que se chama a nossa vida interior é, em parte, resultado do fato de seguir por algum período de tempo uma dessas correntes, o curso de um pensamento que se desenvolve em nós e ao mesmo tempo nas outras pessoas, a ladeira de um pensamento coletivo... Em todo caso, se a partir das durações individuais, é possível reconstituir uma duração mais longa e impessoal na qual aquelas estejam contidas, é porque aquelas mesmas se destacam sobre o pano de fundo de um tempo coletivo ao qual as durações individuais prestam toda a sua substância. (HALBWACHS, 1997, p. 156).

Existe um tempo coletivo que difere da soma de momentos e se opõe às durações individuais. O tempo universal, extenso e uniforme, não contribui para a análise da memória pois não guarda lembrança alguma. Cada grupo social tem seu tempo ou tempos coletivos $^{6}$. Essas temporalidades subsistem paralelamente, mesmo nas sociedades em profunda evolução. Existem muitos tempos coletivos porque há muitas correntes de pensamento e grupos ativando frequentemente os mecanismos da memória. É inadequado falar de tempo universal porque a sociedade é composta por uma multiplicidade de grupos (cada qual com sua temporalidade) e de indivíduos que passam constantemente de um grupo a outro. O tempo universal não consegue uniformizar essa pluralidade temporal, nem

\footnotetext{
6 "Não esqueçamos que os grupos que se comparam não têm nem a mesma natureza nem o mesmo tipo de ocupação... um vilarejo é um vilarejo e é preciso compará-lo a ele mesmo e não a um grupo de outra natureza... O tempo é aquilo que deve ser para cada grupo e segundo as pessoas cujos pensamentos adquiriram traços próprios em função de suas necessidades e tradições" (HALBWACHS, 1997, p. 178).
} 
mesmo através da comunicação moderna. O "tempo social" halbwachiano possibilita a referência à eternidade da memória cultural, à permanência de valores culturais como valores virtuais.

Para que o exercício da memória seja possível, o tempo deve ter certa duração. Essa permanência, diz Halbwachs, permitirá à memória remontar mais ou menos longe no passado. Embora o tempo universal seja inaceitável, é necessário trabalhar com um tempo social estável (mas não inteiramente recuperável pela memória). Temos a ilusão de que o tempo volta à nossa mente da forma como foi vivido, mas não é ilimitada nossa capacidade de lembrar dos grupos de que fizemos parte. Esse limite é dado pelas mudanças nos grupos que integramos. As transformações direcionam nossa atenção para o novo, mas não produzem o esquecimento total dos tempos antigos:

Enquanto o grupo não muda sensivelmente o tempo que sua memória alcança pode se estender: o tempo será sempre um meio contínuo que fica acessível em toda a sua extensão. É quando o grupo se transforma que o tempo novo começa para ele e a sua atenção se desloca progressivamente daquilo que era e daquilo que agora não é mais. Mas o tempo antigo pode subsistir do lado do tempo novo, e nele mesmo, naqueles de seus membros que foram menos atingidos pelas mudanças, como se o grupo antigo recusasse a ser completamente absorvido no grupo novo que saiu de sua substância. (HALBWACHS, 1997, p. 184).

É comum dizer que o tempo passa mais rápido aqui ou acolá. Na cidade, por exemplo, parece fluir mais rapidamente do que no campo. Para Halbwachs, essa noção de velocidade não tem significado definido se aplicada às sociedades reais. $\mathrm{O}$ mesmo não ocorre no processo de lembrança. Quando lembramos, o pensamento percorre instantes num maior ou menor intervalo de tempo. A rapidez da memória varia de um grupo a outro, de um indivíduo a outro e também num mesmo indivíduo segundo diferentes circunstâncias (HALBWACHS, 1997, p. 180).

O tempo é um apoio da memória pelo fato de ser contínuo: no exercício de memória, podemos reencontrar um fato passado. É como se o tempo ficasse imóvel durante um longo período. Para tanto, o grupo que serve de marco social da lembrança não deve mudar sua natureza nem sua estrutura; assim, a atenção será mantida sobre os mesmos objetos. 
Em Les cadres sociaux de la mémoire, fica claro o primado da memória coletiva sobre a individual, mas, na obra La mémoire collective, o autor trabalha com o conceito de "correntes de memória" que acompanham a todo momento os indivíduos que lembram de suas experiências de grupo. O exercício de memória de um indivíduo sempre se apoia na memória do grupo (HALBWACHS, 1997, p. 58). Este não precisa estar fisicamente presente, como ilustra a parábola do "solitário de Londres": toda pessoa continua sentindo a influência da sua sociedade mesmo distanciando-se dela. Como os indivíduos fazem parte de diversos grupos ao mesmo tempo, participam de várias ou muitas correntes de memória. O pensamento individual refletirá esses pontos de vista diversos, de modo que o indivíduo possa reconstituir o passado segundo as consciências coletivas de que fazia parte.

Nos seus primeiros trabalhos, Halbwachs critica a independência da consciência individual mostrando que ela não tem a autonomia defendida por Bérgson: é necessário inseri-la no interior da memória da família, do grupo religioso, da classe. Em La mémoire collective, Halbwachs vincula a memória individual a múltiplas memórias coletivas. Mas as correntes de memória são sua contribuição mais inovadora. A memória individual é colocada no cruzamento das múltiplas correntes de memória, que se tornam autônomas. Essa proposta leva necessariamente à noção de memória cultural, que aqui não discutimos.

\section{Linguagem e memória religiosa}

No capítulo intitulado Le langage et la mémoire (HALBWACHS, 1994) temos as hipóteses principais sobre o papel da linguagem no processo de memória coletiva. Encontramos nesse texto de 1925, vale lembrar, propostas que só na segunda metade do século $\mathrm{XX}$ as neurociências, como a neuroliguística, confirmarão e desenvolverão com consistência inédita. Em relação a esse avanço, recente, do conhecimento científico sobre a linguagem, as hipóteses de Halbwachs parecem precoces. Provavelmente, Halbwachs foi o primeiro (pelo menos na sociologia) a se colocar a questão e a ensaiar uma análise sobre a natureza da 
relação entre linguagem e memória, ambos como fenômenos necessariamente coletivos. Com o objetivo de compreender essa relação, o autor analisa duas situações em que a linguagem é interditada ou reduzida: o sonho e a afasia. E se coloca, para ambos os casos, a questão do que acontece com a memória nessas situações em que a linguagem se reduz. Quanto ao sonho, considera Halbwachs que nele subsiste alguma forma de linguagem deteriorado ao ponto de ser quase impossível compreendê-lo:

Saber que os homens enquanto dormem não param de falar interiormente, mostra algumas das propriedades mais caraterísticas do sonho. Mas, em que consiste exatamente essa linguagem mental que não se percebe nem de dentro (pelo menos de forma clara e consciente), nem de fora? Nos parece que nós só podemos compreender de nossos sonhos aquilo que podemos formular com a ajuda de palavras, e onde, em consequência, sentimos que essas palavras estão a nossa disposição. (HALBWACHS, 1994, p. 58).

Pergunta-se, então, qual seria o papel da linguagem durante o sonho (HALBWACHS, 1994, p. 53). Quanto à afasia, Halbwachs registra que o problema da afasia (das mais diversas formas) já tinha sido objeto de muitas pesquisas e revisa as conclusões das mesmas e propõe a seguinte definição da mesma: a afasia seria uma abolição das lembranças verbais (1994, p. 63). Veja-se que nessa definição está embutida uma relação entre linguagem e memória. Em todo caso, a afasia que lhe interessa é àquela em que a lembrança das palavras não desaparece de forma integral (HALBWACHS, 1994, p. 63).

Como é conhecido, muito recentemente a neurolinguística e a neuropsicologia também se interessaram por analisar situações de afasia para melhor compreender a complexa relação entre cérebro e linguagem. Na época em que Halbwachs escreve, o conhecimento dessa relação é precário ou pouco conhecida: "não sabemos em que consiste o mecanismo cerebral da linguagem, mas, quando falamos nós sentimos que atribuímos significados às palavras e às frases; isto é, sentimos que nosso espírito não está vazio. Por outra parte, quando falamos sentimos que esses significados atribuídos são convencionais (HALBWACHS, 1994, 68). O conhecimento da relação entre linguagem e cérebro tem dado passos gigantes, posteriormente. Na tentativa de explicar como memória 
e linguagem estão associadas o estúdio do fenômeno da afasia tem sido de utilidade, levando a teorias muito diversas, não faltando nelas uma compreensão meramente instrumental da memória, separada e apenas ao serviço da linguagem:

A teorização linguística da segunda metade do século XX, ancorada numa perspectiva comunicacional e informacional da linguagem, ao conceber a linguagem como um instrumento cognitivo privilegiado entre os demais processos, vê na relação entre linguagem e memória um caráter meramente instrumental da primeira em relação à segunda, na qual a memória se reduz a uma espécie de processamento mental da informação. Nessa perspectiva, percebemos que a memória é reputada ao domínio mental, cujo entendimento estaria alheio à ordem da linguagem e seu funcionamento. (CRUZ, 2004, p. 601).

É evidente que essa compreensão “instrumental” da relação entre memória e linguagem é insuficiente. Halbwachs entende que a linguagem é um quadro social da memória de forma semelhante como são o tempo social e o espaço. Na base dessa proposta do autor está a ideia de que graças à mediação da linguagem os seres humanos podem pensar em comum. Sem esses quadros sociais seria impossível a compreensão entre indivíduos. A redução da linguagem, como nos casos da afasia, ou a sua interdição, durante o sonho, causa um impacto na compreensão: "O espaço, o tempo, e os outros quadros que esclarecem e ordenam em certa medida nossas visões noturnas são imagens deformadas e incompletas das noções que permitem que os homens acordados se compreendam" (HALBWACHS, 1994, p. 53). O sonho implica um isolamento da pessoa em relação aos processos sociais em que a linguagem e a memória operam em conjunto. Durante o sonho a linguagem é interditada ou muito reduzida (se pensamos nas pessoas que "falam" quando dormem) e a memória se torna impossível. Durante o sonho os quadros sociais como tempo, espaço e linguagem se tornam tão frágeis que apenas permitem uma memória fragmentada e difusa, que Halbwachs compara aos pedaços de uma peça de porcelana quebrada:

Assim, os quadros como espaço e tempo, onde nós enquadramos nossas percepções e nossas lembranças durante o dia, durante o sonho se encontram elementos da mesma, mas, fragmentários e recortados de forma bizarra, tal como os pedaços irregulares do desenho de uma porcelana quebrada. As imagens do sonho são espaciais e temporais, mas não acontecem num espaço e num tempo onde nós as poderíamos localizar e coordenar. (HALBWACHS, 1994, p. 53). 
Ao mesmo tempo, Halbwachs vê nessa situação como, mesmo nesse estado de isolamento temporário e parcial que é o sonho, que a força das noções elaboradas pelo grupo social ("consciência coletiva”) pode ser reconhecida.

Após uma longa análise de diversas formas de redução tanto da linguagem como da memória no sonho e na afasia, Halbwachs chega à conclusão de que a linguagem, entendida como "convenções verbais" constituem o quadro, ao mesmo tempo elementar e estável da memória coletiva (HALBWACHS, 1994, p. 82). A linguagem é a condição básica da memória coletiva e também a razão de sua constituição.

Algumas teorias recentes das neurociências consideram ser a relação entre linguagem e memória apenas de caráter instrumental, reduzindo a memória a um armazém ao serviço da linguagem:

No campo da Neuropsicologia e da Neurolinguística, o diagnóstico de distúrbios cognitivos relacionados à memória e a linguagem estão tradicionalmente pautados em uma concepção representacional e referencial dos processos cognitivos. $\mathrm{O}$ resultado disto é que a linguagem acaba sendo vista como informação (armazenada e processada pela/na memória) e a memória como armazenamento dessa informação (como estocagem, recuperação imediata, voluntária e consciente do passado). Dessa forma, a única relação possível é a de instrumentalidade (externa e dicotômica) entre esses dois processos. (CRUZ, 2004, p. 602).

Encontramos no pensamento de Halbwachs uma relação entre linguagem de memória que podemos chamar de complementária e não instrumental. As conclusões do que acontece com a linguagem e com a memória resultam de suas análises de diversos casos de afasia e do sonho. Para nosso autor, a memória depende da linguagem e sua perda tem implicações na mesma:

Se a perda ou a alteração da linguagem acarreta maior ou menor dificuldade de lembrar e de reconhecer as lembranças de toda natureza, podemos dizer que a memória em geral depende da palavra. Sendo que a palavra não se concebe senão no interior de uma sociedade, teremos ao mesmo tempo demonstrado que na medida em que ele um homem interrompe seu contato e sua comunicação com os outros, torna-se também menos capaz de se lembrar... Poderíamos nos perguntar, em primeiro lugar, se a afasia implica ou não um problema ou um enfraquecimento da inteligência e, mais precisamente, se ao mesmo tempo que esquecemos as palavras nos tornamos incapazes, pelo menos 
parcialmente, de pensar e de relacionar nossas ideias seguindo as convenções reconhecidas em nosso entorno. (HALBWACHS, 1994, p. 64).

Convêm precisar que para nosso autor, então, tanto a linguagem como o pensamento têm uma função coletiva por excelência:

Nós compreenderemos os outros, sabemos que eles nos compreendem, e, pelo demais, é por essa razão que nós mesmos nos compreendemos: a linguagem consiste, assim, em uma atitude do espírito, que só se pode conceber no interior de uma sociedade, fictícia ou real: trata-se da função coletiva por excelência do pensamento. (HALBWACHS, 1994, p. 68).

Halbwachs conclui o capítulo Langage e mémoire afirmando que "as convenções verbais constituem o quadro, ao mesmo tempo, mais elementar e mais estável da memória coletiva" (HALBWACHS, 1994, 82). Mais estável porque sem elas a própria existência coletiva não parece possível. Mais elementar porque a memória que dela resulta deixa passar muitas coisas, ficando apenas com detalhes isolados de nossas representações. A memória e o esquecimento são concomitantes.

\section{Conclusão}

Os estudos de Halbwachs demonstram de um lado a estreita relação entre memória e linguagem; ao ponto de serem mutuamente dependentes. Sem linguagem não há memória possível, mas, sem memória, a linguagem também seria impossível. Por outro lado, a memória é sempre incompleta, parcial, seletiva, instável. A memória e o esquecimento são concomitantes. É impossível lembrar a totalidade das experiências vividas. Os limites da memória resultam também da riqueza da linguagem, capaz de adquirir múltiplas formas. Apoiados nas reflexões de Halbwachs poderia se dizer que a memória é incapaz de acompanhar a dinâmica da linguagem, sempre passível de adquirir e outorgar novas formas, novos sentidos. A memória recolhe, apenas parcialmente e no instante em que se rememora, fatos vividos reformulando-os. A linguagem sempre é capaz de ir além da memória. Na metáfora da orquestra, analisada no início deste artigo, fica explícita a multiplicidade da linguagem e de memórias possíveis, resultado da multiplicidade de leituras de uma partitura. 


\section{REFERÊNCIAS}

BARRERA, Paulo. Tradição, transmissão e emoção religiosa. São Paulo: Olho d'Água, 2001.

BERGSON, Henri. Essai sur les données inmédiates de la conscience. Paris: Felix Alcan, 1930.

BERGSON, Henri. L’énergie espirituel. Paris: PUF, 1949.

BERGSON, Henri. Matéria e memória. São Paulo: Martins Fontes, 1990.

CRUZ, Fernanda. Da relação entre linguagem e memória: implicações para a neurolinguística. Estudos Linguísticos, Campinas, v. XXXIII, p. 601-606, 2004.

HALBWACHS, Maurice. La classe ouvrière et les niveaux de vie. Recherches sur la hiérarchie des besoins dans les sociétés industrielles contemporaines. Paris: ALCAN, 1913

HALBWACHS, Maurice. La mémoire colletive. Paris: PUF, 1997.

HALBWACHS, Maurice. La morfologie social. Paris: PUF, 1970

HALBWACHS, Maurice. La topographie légendaire des évangiles en Terre Sainte. Étude de mémoire collective. Paris: PUF, 1971 .

HALBWACHS, Maurice. Les cadres sociaux de la mémoire. Paris: PUF, 1994.

NAMER, Gerard. Memóire et société. Paris: Méridiens Klincksieck, 1987.

SAMPÁIO, Evaldo. A virada linguística e os dados imediatos da consciência.

Trans/Form/Ação, Marília, SP, v. 40, n. 2, 2017. 